\title{
Ecologia política e estratégias de sustentabilidade: uma reflexão teórica
}

\section{Political ecology and sustainability strategies: a theoretical reflection}

Nirvia Ravena - Dra. em Ciência Política pelo IUPERJ, Professora do NAEA/UFPA. E-mail: niravena@gmail.com

\section{Resumo}

Este artigo tem como objetivo realizar uma reflexão teórica baseada nos modelos que analisam a relação entre crescimento populacional e acesso e uso de recursos naturais, inserindo nos modelos apresentados para análise dessa relação, a dimensão da posteridade como categoria balizadora das decisões políticas acerca das estratégias possíveis de sustentabilidade. $\mathrm{O}$ artigo apresenta o modelo de Boserup acerca da pressão populacional sobre os recursos, as arguições sobre a liberdade, de Stuart Mill e o modelo sobre Recursos Comuns de Elinor Ostrom.

\begin{abstract}
This article aims to conduct a theoretical analysis based on models that examine the relationship between population growth and access and use of natural resources, including in the models presented for this relationship analysis, the category of posterity as a base for policy decisions concerning possible strategies sustainability. The article presents the model of Boserup about population pressure on resources, the Stuart Mill's complaints about freedom, and the model on Common Resources by Elinor Ostrom
\end{abstract}

\section{Palavras-chave}

Ecologia política. Recursos naturais. Desenvolvimento sustentável.

\section{Keywords}

Politic Ecology. Natural resources. Sustainable development 


\section{INTRODUÇÃO}

Atualmente, a sustentabilidade é palavra dotada de uma irrefutável polissemia. Entre as discussões que potencializam a sustentabilidade como alternativa única num cenário caótico de depredação do ambiente, outra discussão travada ainda nos anos 1960, permanece como elemento balizador de algumas questões relativas à sustentabilidade. Essa discussão associava crescimento populacional à garantia da manutenção dos padrões atuais de recursos naturais para as gerações posteriores. Este artigo percorre parte da literatura acerca da relação entre crescimento populacional e utilização dos recursos naturais inserindo na compreensão dos modelos explicativos a dimensão política das gerações posteriores como sujeitos desse processo.

A herança malthuseana parece influenciar de forma decisiva os modelos que tratam da relação entre o crescimento populacional e as formas de produção. A imutabilidade nos processos de produção de alimentos e a inexistência de possíveis alternativas à "inexorável” pressão populacional não consideraram a variável tecnológica. Modelos mais contemporâneos consideram como central essa variável e apresentam alternativas que negam o pressuposto da estagnação. Nesses modelos, a pressão advinda do crescimento populacional seria, portanto, o elemento propulsor das mudanças tecnológicas ou de organização social que ocorreram nas formas de produção da sociedade. Incluem-se nessas novas tecnologias, aquelas resultantes das mudanças institucionais. Enquanto formas atuais das mudanças no acesso e uso dos recursos naturais, as alterações nas formas de gerir tais recursos são significantes. Recursos comuns, portanto, não se inscrevem nas formas dominantes de acesso e uso de recursos naturais presentes no contexto capitalista. A inovação resultante das estratégias de uso desses recursos é o elemento central de uma mudança institucional que ocorre paralelamente a uma mudança tecnológica.

Este artigo procura elaborar uma análise das questões relativas ao acesso e uso de recursos naturais utilizando a ecologia política como eixo condutor dessa análise. São apresentados os modelos que associam mudança tecnológica e crescimento populacional, com também a teoria que dá suporte à interpretação dos recursos comuns, incluindo a mudança institucional.

\section{TECNOLOGIAEAGRICULTURA:ASPRESSÕESEAS ALTERNATIVAS}

O modelo apresentado por Boserup (1987), para explicar o desenvolvimento da agricultura, adota a perspectiva de que as mudanças tecnológicas são, na maioria das vezes, escolhas oriundas da pressão populacional sobre os recursos. O eixo de sua análise recai sobre a frequência do cultivo. Este conceito é tomado no intuito de relacionar mudança técnica e fatores econômicos à posse e uso da terra, e desta forma, a autora propõe demonstrar que a mudança tecnológica não é um fator autônomo e independente da dinâmica populacional. Contrapondose aos neoalthusianos, Boserup (1987) acredita que a alteração nos métodos de cultivo pode introduzir inovações, como irrigação, adubação e outras técnicas que permitam que determinadas áreas que antes abrigavam poucas pessoas passem a ter suporte para responder a um considerável aumento populacional. A recuperação de solos estéreis através de técnicas modernas se apresenta como alternativa viável para aumentar a capacidade de suporte do planeta (BOSERUP, 1987, p. 19-20).

A relação estreita entre mudança técnica e uso da terra, conforme apresentado por Boserup, pressupõe que há uma concomitância entre novas formas de cultivo e novas ferramentas. Boserup (9187), portanto, rejeita, a "inventividade de um povo" como categoria pertinente à análise dessas mudanças. Utiliza a alteração dos sistemas de pousio em função da necessidade advinda da pressão populacional como condição apriorística à introdução de novas ferramentas e técnicas. A enxada e a fertilização com adubo animal são exemplos (BOSERUP, 1987 , p. 24, 25, 26). Contudo, a quantidade de trabalho adicional necessária quando determinada sociedade atinge uma densidade populacional, a qual impulsiona a mudança na técnica de cultivo, muitas vezes supera a produção necessária para subsidiar a mudança em curso, isto principalmente, quando se trata de fertilização, utilização de tração animal e irrigação ${ }^{1}$.

Outro elemento de análise central na perspectiva de Boserup (1987) acerca da correlação entre pressão demográfica, intensidade do uso da terra e mudança tecnológica, é o número de horas despendido em cada tipo de agricultura. A autora supõe que antes da necessidade de mudanças no padrão de uso da terra

Boserup (1987) propõe que mesmo com as técnicas disponíveis, a mudança só é adotada quando se atinge uma determinada densidade populacional. Boserup descreve o aumento da capacidade de suporte quando se transita de sistemas de cultivo de pousio longo com enxada para um sistema de pousio curto com arado e tração animal. Descreve também este aumento para outras técnicas como o cultivo de forrageiras e leguminosas e irrigação associada a colheitas múltiplas (BOSERUP, 1987, p. 39-42). 
e de técnicas de produção em função do aumento da população, determinadas sociedades não abrem mão das horas de lazer para obter uma produção adicional. Utilizando exemplos de sociedades menos complexas, Boserup contrapõe-se à ideia de desemprego estrutural rural. Para a autora, a estreita relação entre disponibilidade de terras e pressão demográfica explica de certa forma a transição do hábito do trabalho para a "necessidade". Boserup considera que em sociedades menos complexas que utilizam a técnica de pousio longo e têm abundância de terras e pequena inversão de trabalho em atividades de subsistência, há uma tendência da comunidade em evitar o trabalho pesado e que o complemento às necessidades de alimentos pode ser encontrado em atividades prazerosas como caça, pesca e coleta de alimentos. Novamente a autora recorre à explicação de que a pressão populacional desempenha papel determinante na alteração dos padrões de dispêndio de horas de trabalho. Sugere que há uma persistência na opção pelo pousio longo mesmo que com certo crescimento populacional haja necessidade de que a quantidade de trabalho seja maior para conseguir a mesma quantidade de alimento.

Ao analisar os diversos sistemas de cultivo e sua simultaneidade no tempo e no espaço, Boserup (1987) demonstra que a pressão populacional é que define o "progresso" técnico adotado historicamente. Sugere que em tempos de diminuição da pressão demográfica por catástrofes ou guerras a volta a sistemas de cultivos mais extensivos se torna a opção adotada pelas comunidades ${ }^{2}$. A autora rejeita a hipótese de regressão técnica e entende este movimento como fruto de uma escolha racional dos produtores em função da relação entre disponibilidade de recursos e número de habitantes. Contudo, adverte que o crescimento rápido da população deve ser acompanhado por uma rápida adaptação a ritmos de trabalho mais árduos em função da intensificação do uso da terra (BOSERUP, 1987, p. 70-72).

O modelo de Boserup (1987) parece ser de certa forma suficiente para explicar movimentos de intensificação do uso da terra em função da pressão demográfica. Contudo, um elemento que não é destacado em seu modelo é a pressão exógena exercida por mercados, sejam eles mercados locais ou mesmo a intensificação exigida por certa forma de coerção econômica promovida por

\footnotetext{
Exemplos como o da Europa após a guerra dos trinta anos e do Japão no período de 1600 a 1850 são tomados para descrever como, somente após um determinado nível populacional ser atingido, passa a haver a incorporação do hábito de se trabalhar mais arduamente e investir em técnicas que promovam um aumento da produção para além da subsistência. A América Latina é o cenário que permite a verificação da importância da estreita relação entre nível tecnológico e pressão demográfica. A autora demonstra que o declínio populacional promoveu um retorno a práticas que exigiam menor inversão de trabalho para o provimento de seus habitantes.
}

políticas econômicas empreendidas pelo Estado³. Netting (1993) desenvolve uma argumentação acerca do papel exercido por mercados na intensificação do uso da terra na busca de produção excedente, complementar à perspectiva de Boserup. Baseado nos estudos de Von Thünen (análise da relação entre produtos, custo de transporte e preços de mercado) e postulados neoclássicos da teoria da escolha racional, conclui que não são excludentes como elementos explicativos as variáveis pressão demográfica e pressão do mercado. Para Netting (1193, p. 294), “[...] demografic and economic factors are part of the same local ecosystems, and in general reinforce each other [...]". Portanto, a íntima relação entre população e meio ambiente parece incluir uma complexidade maior que engloba a organização social como variável importante. Todavia, as formas de apropriação dos recursos para além da subsistência devem inserir, não somente o mercado, mas também as formas assumidas por conflitos pelo acesso a recursos que findam definindo a hierarquia interna das diversas sociedades. Boserup assume que a exigência de trabalho adicional e as formas de pressão sobre os recursos podem advir de uma compulsão exercida por determinada hierarquia social (BOSERUP, 1987, p. 60).

\section{O APARECIMENTO DO ESTADO NUMA PERSPECTIVA AMBIENTALISTA}

Há um elo entre modelo de Boserup (1987) e a perspectiva assumida por Robert Carneiro (1970) para explicar uma organização social específica, o Estado. Ambos adotam a premissa de que a pressão sobre os recursos em função do aumento do número de indivíduos em uma determinada sociedade é o motor do desenvolvimento da humanidade. Na perspectiva de Carneiro, o "nascimento" do Estado se dá em função também da pressão causada pelo aumento populacional, mas, fundamentalmente, da pressão sobre os recursos, através da delimitação de territórios pelos diferentes grupos humanos com técnicas diferenciadas ou similares. Um processo marcado pela competição finda por delimitar conflitos por maior acesso a recursos ou mesmo para manter uma exploração de recursos já em curso.

As hipóteses voluntaristas de aparecimento do Estado são rejeitadas por Carneiro ${ }^{4}$, que constrói um paradigma diferenciado que associa a circunscrição

Barlet (1976) exemplifica a intensificação também a partir das pressões do mercado.

${ }^{4}$ Estas hipóteses têm como base a teoria contratualista e pressupõem, que espontânea, racional 
ambiental à circunscrição social para explicar a emergência do Estado. Acompanhando a premissa de Boserup da pressão demográfica sobre recursos, Carneiro interpreta que o limite imposto pela incorporação de todas as terras disponíveis e a indisponibilidade de novos recursos, principalmente terras agricultáveis, induz à delimitação de territórios através de conflitos por recursos. A guerra, portanto, é um elemento central na definição de territórios e na criação de hierarquias sociais que podem extrair de novos territórios recursos adicionais através de tributos cobrados aos vencedores, o que iniciaria um processo de diferenciação social e formação de elites no interior dos grupos. Carneiro denomina este processo de circunscrição social. Esta categoria de análise baseia-se no pressuposto de que o número de habitantes num mesmo território pode induzir aumento de conflitos. Haveria neste modelo, uma área central com alta densidade populacional. Considerando que as áreas próximas à central são território de outros grupos, o total da área já teria habitantes suficientes para a exploração da área e portanto novamente a lógica do conflito se estabeleceria e conjuntamente à essa lógica se estabeleceriam lideranças responsáveis pela defesa e pela busca de novos recursos $^{5}$. O paradigma de Carneiro limita-se a sociedades em que as instituições políticas de certa forma não experimentam a especialização das organizações. Sua teoria explicaria, numa perspectiva cultural e ecológica, a gênese do Estado. Contudo, as formas mais complexas de organização social são características de um tipo de Estado: o Estado moderno. Apenas a partir da relativização e da sofisticação do modelo de Carneiro é que poderiam ser aplicadas as variáveis de seu modelo a um grau mais complexo de institucionalização das relações sociais.

e voluntariamente em algum momento da história determinados grupos humanos abriram mão de sua soberania individual (direito natural, na linguagem hobbesiana) para unir-se a uma organização política mais complexa que garantiria estes direitos: o Estado. A teoria voluntarista, baseada na divisão do trabalho, supõe que várias unidades autônomas e especializadas integraram-se na unidade denominada Estado. Esta perspectiva, certamente, consiste numa abordagem "antropológica" do aparecimento do Estado que certamente diverge da teoria política, mas que se insere nesta discussão por tratar-se do conceito de Estado com o qual, na maioria dos casos, os ambientalistas operam.

5 A base empírica para a construção do modelo de circunscrição social elaborado por Carneiro para complementar sua teoria de circunscrição ambiental se assenta nos estudos de Napoleon A. Chagnon acerca dos índios Ianomani da Venezuela (CARNEIRO, 1970, p. 737). Anna Roosevelt adota a perspectiva de Carneiro acerca da formação de cacicados na Amazônia ter se constituído mais tardiamente que nos Andes Centrais. Todavia, relativiza a teoria da circunscrição social por entender que para a Amazônia, muito tempo seria necessário para que fosse preenchida a vastidão dos habitats disponíveis. Defende a ideia de que os grupos amazônicos adaptaram-se à concentração populacional em áreas com abundância de recursos até um limite crítico e que somente nesse momento o acesso a esses recursos ficou preferencialmente aos vencedores dos conflitos (ROOSEVELT, 1991, p. 126-127).
Outras formas de complexificação foram experimentadas pela humanidade e a pressão causada pelo aumento da população sobre os recursos não foi acompanhada por mudanças tecnológicas ou de organização social suficientes para a manutenção da capacidade de suporte dessas civilizações ${ }^{6}$.

Joseph A. Tainter (1988) adota a perspectiva de colapso para explicar este movimento. Sua interpretação para explicar o colapso em sociedades complexas advém dos postulados da teoria integracionista que permite verificar a relação entre sistemas distributivos para os recursos necessários à vida e à teoria do conflito por recursos. De forma sintética, o modelo proposto por Tainter diagnostica que o colapso em sociedades complexas ${ }^{7}$ adveio dos custos adicionais necessários para a manutenção da complexidade organizacional da sociedade desproporcionais aos retornos desses investimentos. Os custos de legitimação e reinforcement nas sociedades complexas constituem-se em elementos centrais para sua manutenção ou propensão ao colapso.

A interpretação da complexidade de determinadas sociedades é fundamental para a compreensão de um momento em que a mudança nos padrões tecnológicos de exploração de recursos permitiu um aumento na capacidade de suporte de determinada sociedade. 


\section{A REVOLUÇÃO INDUSTRIAL COMO CAUSA E EFEITO}

A interpretação de Wilkinsson (1974) acerca do advento da Revolução Industrial exemplifica este momento. Em uma perspectiva histórica, este autor interpreta a Revolução Industrial como uma resposta à exaustão da exploração de um recurso fundamental na Inglaterra: a terra. Considerando as pressões demográficas oriundas do aumento populacional ocorrido entre os séculos XVI e XVIII e a limitação territorial, os métodos de subsistência passaram a ser inadequados e a tecnologia tradicional utilizada pelas indústrias chegou a um ponto de estrangulamento: a transformação cada vez maior das florestas em terras aráveis e uma procura cada vez maior de madeira como combustível industrial e doméstico. A substituição de lenha por carvão foi uma resposta a uma pressão ecológica e as inovações tecnológicas presentes na Revolução Industrial foram um desdobramento desse processo de substituição de um recurso por outro.

Wilkinson descreve os momentos de transformação dos padrões tecnológicos de diversos setores como adaptação de técnicas já em uso para um novo tipo de combustível descoberto em função da escassez do que era anteriormente utilizado. Para Wilkinson até o momento da escassez de madeira para as suas diversas utilizações, foi racional o uso desse recurso onde este se mantivesse abundante ${ }^{8}$. A díade escassez e abundância permeia a análise de Wilkinson. A energia a vapor foi um resultado da escassez de outras fontes, como a hidráulica que dependia de quedas d'água, e a força animal que dependia da produção de forrageiras para o alimento dos animais numa situação de escassez de terras. O carvão como fonte de energia, ao contrário, era abundante e podia ser adquirido na boca da mina. Estes foram fatores ecológicos para o impulso e a difusão da energia a vapor?.

8 Munford descrevendo um padrão tecnológico da sociedade europeia, denominado de eotécnico, argumenta que como matéria-prima, ferramenta, engrenagem, máquina, combustível e utensílio a madeira era o recurso dominante na fase eotécnica e permaneceu após o advento da era industrial Sua substituição por metal foi gradativa, permanecendo em madeira grande parte das engrenagens das máquinas (MUNFORD, 1934, p. 120). A fase posterior, denominada paleotécnica, na opinião de Munford, foi fruto de saberes e mudanças institucionais acumulados no longo período da fase eotécnica (MUNFORD, 1934, p. 151).

Hugill interpreta esta passagem também sob a ótica da escassez e adiciona alguns elementos explicativos à passagem da fase eotécnica para a fase paleotécnica. Primeiramente a queda da produção nos sistemas que utilizavam rodas d'água. Os níveis pluviométricos findavam por limitar a produção. Em segundo lugar, a dispersão da escala de produção em termos espaciais que limitava a produção crescente. Em terceiro lugar, o dia de trabalho, mesmo com a concentração de trabalhadores em ambientes fechados, era limitado pela luz do dia. A introdução do carvão e seus derivados possibilitou, segundo Hugill, a transposição desses limites (HUGILL, 1993, p. 71-72).
A divisão internacional do trabalho pode ser interpretada como um passo importante para o entendimento da superação de um limite da capacidade de suporte da sociedade europeia.

A lógica da intensificação da produção associada à lógica do conflito pela exploração de recursos surge em uma sociedade cujo nível de complexificação e passa a ser também elemento importante para a manutenção da capacidade de suporte. A primazia tecnológica associada à complexificação das instituições, portanto, permitiu que outras áreas fossem anexadas para a produção de bens necessários à vida sem que isso significasse uma melhoria equitativa para todos os habitantes envolvidos por essa lógica.

\section{A PREDAÇÃO DO MODELO: REVOLUÇÃO INDUSTRIAL E RECURSOS NATURAIS}

O advento da Revolução Industrial deixou como herança uma era em que rapidamente os recursos foram exauridos em função da busca da manutenção da capacidade de suporte de uma sociedade. A categoria capacidade de suporte, porém deve inserir em seu modelo de análise outras variáveis como sugere Glassow (1978). O modelo de pressão populacional sobre os recursos que incorpora a análise da capacidade de suporte deve ser utilizado em circunstâncias de rápido crescimento populacional e modificação ambiental. A complementarização com a análise dos custos da exploração de recursos e tecnologia permite a inserção de fatores econômicos na análise que poderiam contribuir na elaboração de cenários onde a quantificação da relação exploração de recursos e tecnologia oferecesse alternativas às estratégias em uso. Esta ponderação é válida, sobretudo, numa economia globalizada. Se os modelos explicativos até agora oferecem alternativas baseadas em experiências de sociedades menos complexas, pergunta-se: qual a alternativa para uma sociedade global com ilhas de menor complexidade que são cada vez mais coagidas pela sociedade envolvente?

As teorias advindas da mudança institucional oferecem um caminho alternativo a esta questão. A base da arguição é a distribuição, as formas de acesso e a intensidade na utilização dos recursos. Mesmo tendo a teoria do conflito como elemento central para a análise, a mudança das instituições atrelada à análise dos custos econômicos (NORTH, 2005) e da capacidade de suporte do planeta pode 
oferecer alternativas além daquelas diagnosticadas apenas a partir de experiências em sociedades com menor complexidade tecnológica e compreender a diversidade institucional (OSTROM, 2005) como pressuposto de inovação.

O advento do Estado e da tecnologia foi inexorável. A alternativa a essa inexorabilidade parece estar associada a uma mudança que garanta recursos para as gerações posteriores mantendo níveis de bem-estar para toda a humanidade. Nesse sentido, outra discussão se apresenta: a discussão acerca de como a humanidade "agora" incorpora em suas ações uma concepção de "gerações posteriores". A discussão, então, deixa de ser técnica e transita para a esfera moral das interpretações acerca da sustentabilidade.

\section{TERÁ UTILIDADE A POSTERIDADE?}

A comunidade científica, em 1968, assistindo, no mundo todo, a vários movimentos sociais contestadores, surpreendia-se com o texto conservador do biólogo Garret Hardin publicado na revista Science. O texto, na corrente contrária aos movimentos libertários, prescrevia o cerceamento das liberdades individuais. O motivo: evitar que o colapso dos recursos naturais do planeta não se efetivasse.

É importante que seja contextualizada a posição "conservadora" do texto, pontuando sua argumentação central. O artigo "A tragédia dos comuns", de Garret Hardin, surgiu em meio a uma preocupação crescente da comunidade científica com a relação entre o crescimento populacional no planeta e a disponibilidade de recursos naturais. No final da década de 1960, as curvas de crescimento populacional nos países em desenvolvimento atingiam níveis preocupantes, e biólogos entraram em cena, explicando as causas desse crescimento e prescrevendo ações. $\mathrm{Na}$ base das análises e prescrições encontrava-se a retomada das teorias malthuseana e darwinista.

Hardin inicia o artigo descrevendo um cenário onde uma área de livre acesso é utilizada por vários pastores. A capacidade de suporte da área mantinha-se abaixo de seu limite em função de eventos naturais como doenças e guerras que findavam por regular a relação entre o número de homens (e seus animais) e o pasto da área. Entretanto, cada pastor passa a incrementar seu rebanho com mais uma cabeça de gado, e isto significa um ganho individual absolutamente racional, dado que, o custo dessa ação (a sobre-exploração do pasto) é compartilhada por todos os que utilizam a área. O ponto da questão consiste na seguinte situação: todos os pastores são racionais e agem similar e simultaneamente. Esta condição Hardin denomina de lógica dos comuns.

É neste ponto que a liberdade individual significa o colapso do coletivo. Garret Hardin busca estabelecer uma metáfora entre "A tragédia dos comuns" e o crescimento populacional que se apresentava como uma situação inexorável. A liberdade humana para a reprodução assemelha-se, na argumentação de Hardin, à liberdade dos pastores em adicionar mais uma cabeça de gado ao rebanho. A sobre-exploração de recursos comuns e o colapso seriam então a resultante da liberdade humana para procriar.

Mesmo considerando que o artigo de Hardin centrava a discussão da liberdade, no contexto da reprodução humana e nas consequências da superpopulação, seu artigo foi e ainda é referência para as análises voltadas à explicação da ação coletiva na apropriação e gestão de recursos comuns.

É nesta perspectiva que suas ideias introduzem uma abordagem intrigante acerca da liberdade. E uma questão absolutamente racional se coloca: qual o grau de liberdade das gerações atuais no acesso a recursos comuns e qual o direito das gerações futuras a esses recursos? Nesse sentido, a interface com a obra "On liberty” de John Stuart Mill parece inevitável ${ }^{10}$.

As razões para essa interface se apóiam no caráter inverso das proposições da obra de Stuart Mill e do artigo de Hardin que findam contribuindo para a reflexão de uma mesma questão. Explica-se: se para Garret Hardin a liberdade individual levada ao extremo é a condição da ruína coletiva, a preocupação de John Stuart Mill assenta-se nos limites que devem ser impostos à coletividade na interferência que esta exerce sobre a esfera individual.

Mas se a abordagem desses autores acerca da liberdade parte de pressupostos diferenciados e opostos, ambas contribuem na reflexão acerca de um argumento central na formulação de políticas destinadas ao uso e controle de recursos comuns: a posteridade.

O pensamento de John Stuart Mill sobre a liberdade está em grande parte atrelado à discussão da liberdade de opinião. Contudo, a abrangência de

10 As abordagens da questão colocada por Hardin, geralmente, são discutidas à luz dos contratualistas ou da teoria da ação coletiva. Na perspectiva contratualista, Willian Ophuls (1972) oferece uma justificativa ao conservadorismo de Hardin a partir de uma concepção hobbesiana para a normatização do acesso aos recursos comuns. Na perspectiva da Teoria da ação coletiva, Elinor Ostrom (1990) oferece uma interpretação interessante acerca de novos arranjos institucionais na apropriação e manejo de recursos comuns. Entretanto, em ambos está ausente uma discussão mais detalhada da liberdade. 
seu conceito de liberdade instrumentaliza a reflexão acerca da liberdade em outros contextos da interação dos indivíduos em sociedade. Stuart Mill parte de pressupostos claramente associados à utilidade, sem recorrer aos conceitos de direito abstrato para estabelecer o escopo de sua arguição. $\mathrm{O}$ autor deixa claro em seu ensaio qual seu objetivo: defender um princípio de liberdade que, de certa forma, normatize a intervenção da sociedade na esfera individual ${ }^{11}$.

É no reconhecimento do outro que o autor estabelece os limites da ação. Stuart Mill recusa a ideia de um direito individual abstrato que não seja atrelado à utilidade. O conceito de utilidade invocado por Stuart Mill está profundamente associado à ideia de progresso ilimitado do homem. Este conceito, apoiado na doutrina "Bildung", de Whilhelm von Humboldt, admite que o desenvolvimento da capacidade individual só encontra limite na possibilidade desse desenvolvimento causar dano a alguém.

Nesse sentido, Stuart Mill é claro quando opera com o conceito de utilidade “[...] Eu encaro a utilidade como a última instância em todas as questões éticas, mas a utilidade no seu mais largo sentido, a utilidade baseada nos interesses permanentes do homem como ser progressivo [...]" (STUART MILL, 1942, p. 35). O recurso utilizado pelo autor para estabelecer o limite entre a liberdade individual e o outro, é que pontua a soberania individual em relação ao corpo e ao espírito.

Essa soberania, contudo, estabelece o caráter relativo da liberdade em relação ao outro. É recorrente na retórica de Stuart Mill, a submissão do interesse individual, que inexoravelmente se apresenta aos homens como instrumento do progresso, ao controle exterior. A condição para a existência de um controle é exatamente a direção tomada pelo interesse individual. Se a ação do indivíduo tangenciar o interesse alheio, ela é passível de controle social.

Cabe aqui retornar ao argumento central de Garret Hardin: a necessidade da coerção da ação individual que é característica da lógica dos comuns.

A semelhança entre as prescrições de Hardin e as arguições de Stuart Mill, assenta-se no recurso ao critério de utilidade para propor princípios de normatização da conduta individual.

"[...] Consiste esse princípio em que a única finalidade justificativa da interferência dos homens, individual e coletivamente, na liberdade de ação de outrem é a autoproteção. $O$ único propósito com o qual se legitima o exercício do poder sobre algum membro de uma comunidade civilizada contra sua vontade, é impedir dano a outrem [...]” (STUART MILL, 1942, p. 33-34).
A percepção de Hardin da liberdade também se assenta no limite da ação em relação ao outro ${ }^{12}$. Abrir mão da liberdade parece ser a prescrição de Hardin. Contudo, seria interessante deslocar a discussão para o eixo do reconhecimento do outro enquanto elemento balizador das reflexões dos dois autores acerca dos graus de liberdade das ações individuais.

O que diferencia Stuart Mill dos contratualistas são os pressupostos tomados por ele para sugerir uma engenharia institucional que estabeleça limites à ação do coletivo na esfera individual. Não são os ganhos pessoais ou individuais ${ }^{13}$ que estabelecem o escopo da engenharia institucional proposta por Stuart Mill. O desenvolvimento de todas as potencialidades do homem somente ocorre em ambiente de total liberdade de pensamento, associação e expressão. Mas essa liberdade só é possível na medida em que o indivíduo reconhece o limite imposto pela existência do outro. É este o ponto de inflexão que permite a introdução de um o conceito mínimo do que se entende aqui por posteridade.

A posteridade é o outro, que está situado em outro tempo e espaço, mas não deixa de existir. Uma definição plausível de posteridade é fornecida por Keneth Boulding (1972). Para o autor, indivíduos somente existem quando podem se identificar com outros num continum de tempo que vai do passado ao futuro.

A questão colocada por Boulding tenta apresentar argumentações mais sólidas para dilemas enfrentados pelos conservacionistas na década de 1970 e que ainda persistem atualmente. Bolding já diagnosticava o problema da justificativa da posteridade situando os indivíduos em um laço que transcenderia o tempo e o espaço $^{14}$. Assim como em Hardin, Boulding também coloca o limite à liberdade individual com vistas à preservação de recursos naturais para as gerações posteriores como um problema, cuja solução não é técnica e sim ética. Para o autor, a menos que o indivíduo compartilhe da perspectiva de identidade apresentada por ele, é

12 "[...] every new enclosure of the commons involves the infringement of somebody's personal liberty. Infringements made in the distant past are accepted because no contemporary complains of a loss. It is the newly proposed infringements that we vigorously oppose; cries of "rights" and "freedom" fill the air. But what does "freedom" mean? When men mutually agreed to pass laws against robbing, mankind became more free, not less so. Individuals locked into the logic of the commons are free only to bring on universal ruin; once they see the necessity of mutual coercion, then they become free to pursue other goals [...] (HARDIN, 1968, p. 142).

13 Em, Hobbes, por exemplo, são os ganhos individuais que substanciam a arguição da perda da liberdade para a constituição de uma engenharia institucional que garanta as leis naturais.

14 “[...] It is always a little hard to find a convincing answer to the man who says, "What has posterity ever done for me?" And the conservationist has always had to fall back on rather vague ethical principles postulating identity of the individual with some community or society which extends not only back into the past but forward the future [...]" (BOULDING, 1972). 
absolutamente irracional qualquer ação que não maximize o bem estar das gerações atuais em função da posteridade.

A interpretação da "Tragédia dos comuns" no âmbito do modelo hobbesiano, torna a análise refém do âmbito normativo. Stuart Mill, como liberal, possibilita uma reflexão inicial acerca de uma engenharia institucional relativa ao direito das gerações posteriores aos recursos naturais, pois, o conceito de Stuart Milll acerca da liberdade assume moldes contratualistas, e as aplicações de seus princípios de liberdade responsabilizam, de forma explícita, as gerações atuais pela garantia da sobrevivência das gerações futuras ${ }^{15}$.

O que torna as proposições de Stuart Mill mais eficazes na justificativa da limitação da liberdade de ação do indivíduo ao acesso e uso de recursos naturais que irão escassear ou faltar às gerações futuras, é a possibilidade de poder operar com um conceito de liberdade relativa dentro de uma perspectiva utilitarista. Preservar e conservar nesta perspectiva transita da moralidade para a necessidade. Há, portanto, a possibilidade de inversão da questão "What has posterity ever done for me?"16 na seguinte indagação "O que temos que fazer pela posteridade?"

O postulado básico da sustentabilidade pode, portanto, ser encontrado nas premissas utilitaristas, o que tornaria confortável a manutenção das formas de exploração de recursos naturais em bases capitalistas. No entanto, Polanyi (1944) é profético ao relatar as consequências da mercantilização de todos os elementos necessários à vida. A complexificação nem sempre é eficiente na mediação que ocorre entre homens e recursos naturais (POLANYI, 1944; TAINTER, 2000). Os autores pontuam que estratégias menos complexas de acesso e uso de recursos naturais e de interação entre o indivíduo e a coletividade são possíveis e podem ser exemplo de sustentabilidade ou colapso. Nessa direção, outro modelo interpretativo da questão sobre acesso e uso de recursos naturais por indivíduos ou coletividades se delineia.

15 “[...] O fato em si de dar existência a um ser humano, é uma das ações de maior responsabilidade na sequência da vida. Assumir essa responsabilidade - conceder uma vida que pode ser uma maldição ou uma benção - sem que o ser vindo à luz conte, ao menos, com as probabilidades ordinárias de uma existência desejável, é um crime contra esse ser [...]”" (STUART MILL, 1942, p. 189).

16 A obra "Ecology and the politics of scarcity" (1977) de Willian Ophuls tornou-se referência na área de políticas ambientais e relações internacionais e em suas primeiras páginas apresenta a seguinte dedicatória: "À posteridade que não tem feito nada por nós". A ironia de Ophuls direcionava-se, também, à dificuldade que os ecologistas ainda enfrentavam na defesa da posteridade como sujeito que balizaria as políticas ambientais internacionais de longo prazo Contudo, a solucão apresentada por este autor recai na perspectiva contratualista de normatização das relações entre liberdade individual, acesso e utilização de recursos naturais e posteridade.
A díade coletivo-individual no acesso e uso dos recursos naturais baliza os fundamentos da Teoria dos Comuns (Common Pool Resources) de Elinor Ostrom (1990). A abordagem da autora baseia-se na teoria da ação coletiva de Olson (1965), na Tragédia dos Comuns de Hardin (1995) e nas teorias neo-institucionalistas. Essa preciosa junção permite que as questões de acesso e uso de recursos que têm características semelhantes ao bem público, mas que padecem das adversidades da subtraibilidade e da excludabilidade sejam tratadas com precisão no modelo acerca de Common Pool Resource apresentado por Ostrom.

Outros modelos de interpretação acerca de Common Pool Resources (CPR) também se apóiam na tipologia dos recursos comuns e das formas de acesso e uso destes (OSTROM et al. 1994, 2003; AGRAWAL, 2002). O termo Commom Pool Resources refere-se a um recurso natural (como águas subterrâneas ou recursos pesqueiros, por exemplo) ou construído (como um sistema de irrigação, por exemplo), suficientemente grande e custoso quando é objeto de apropriação e/ou provimento, mas que ao mesmo tempo permite a exclusão de potenciais beneficiários de seu uso. Para E. Ostrom (1990) há uma importante distinção na análise de CPR em relação ao conceito de benefícios públicos. $\mathrm{Na}$ análise dos Recursos Comuns, há o sistema do recurso, e as unidades de recursos. Esta diferença é muito importante em função da característica do recurso. O sistema do recurso compreende o estoque de variáveis que permitem, em condições favoráveis, a produção de um máximo de unidades de recurso sem danificar o estoque original. Esta dessemelhança é fundamental para o estudo de recursos naturais como recursos pesqueiros, águas subterrâneas etc. É esta distinção que permite a avaliação do grau de reposição do recurso, em quantidade para manter o sistema de recursos sustentável no tempo.

As categorias de bem coletivo, tamanho do grupo, incentivos seletivos e evidência de comportamento constituem o eixo sobre o qual a análise acerca da apropriação desses recursos como também os modelos de gestão são compreendidos. Os novos formatos institucionais que resultam do acesso e uso dos recursos comuns são a argumentação central desse modelo.

A Teoria da Ação Coletiva direcionava-se ao estudo da ação no provimento de bens públicos (OLSON, 1965), e foi importante para a análise dos Recursos Comuns, e para perceber as nuances que estabelecem sutis, mas importantes, diferenças entre Benefícios Públicos e Recursos Comuns como, por exemplo, as características de incapacidade de exclusão e subtraibilidade respectivamente. 
Tanto Benefícios Públicos quanto CPR têm problemas quanto à ocorrência de comportamentos do tipo free rider, mas as unidades de CPR, uma vez consumidas, reduzem o estoque do recurso. Um Benefício Público como segurança, por exemplo, se consumido por mais beneficiários do que aqueles que empreenderam a ação na provisão desse bem, não diminui o "nível" total do benefício ${ }^{17}$. A distinção entre Benefício Público e CPR, portanto não é trivial. Uma pessoa que contribui para a provisão de um Benefício Público não se importa com quem mais consumirá este benefício, onde e quando e se houve por parte deste beneficiário uma contribuição suficiente nos custos de provisão do bem. Para quem se apropria e/ou provê um CPR é realmente importante a informação de quantos são os que vão acessar o recurso, quando, onde e se todos contribuíram para a provisão do CPR.

Assim, os desenhos institucionais para a o acesso e uso de recursos comuns não são elementos triviais nas discussões sobre sustentabilidade.

Se a mudança experimentada a partir da Revolução Industrial depredou e esgotou recursos de forma rápida e deixou escombros, isto pode ser mudado, principalmente através da mudança no acesso e uso dos recursos naturais. A advertência de Lewis Munford ${ }^{18}$, para a mudança, ainda 1934 era pertinente.

A decisão pela busca da sustentabilidade da exploração dos recursos necessários à vida, portanto, parece ser política, cultural e fundamentalmente de escolha institucional. Se a humanidade, em especial, a civilização ocidental experimentou momentos de escassez e conseguiu superá-los, com base em sistemas que não garantiam a equidade no acesso e provocaram a dilapidação dos recursos, o salto qualitativo está em encontrar o dia em que a inteligência e a cooperação social sejam alcançadas no intuito de promover a permanência da vida no planeta.

\footnotetext{
17 E. Ostrom pontua esta questão de forma elucidativa "[...] What makes the problem more difficult in a C.P.R situation than in a publics good situation is that unlees appropriation problems are resolved, the provision problems may prove intractable. In a public-goods situation, appropriation problems do not exist, because resource units are not subtractable [...] (OSTROM, 1990, p. 49).

18 " [...] But is not all slag: far from it. One can even now look forward to the day when the poison gases and caked refuse, the once useless by-products of the machine, may be converted by
} intelligence and social cooperation to more vital uses [...]" (MUNFORD, 1934, p. 106).

\section{REFERÊNCIAS}

AGRAWAL, A. Rules, rule-making and rule-breaking. In: OSTROM, E.; GARDNER, R.; WALKER, J. Rules and games. East Lansing: Michigan University Press. 1994. p. 267-282

BARLET, P. F. Labor Efficiency and the Mechanism of Agricultural Evolution. Journal of Anthropological Research, v. 140, n. 1, p. 124, 1976.

BOSERUP, E. Evolução agrária e pressão demográfica. São Paulo: Hucitec, 1987.

BOULDING, K. E. The economics of the coming spaceship earth. In: NELISSEN, Nico; VAN DER STRAATEN, J.; KLINKERS, Leon. Classics in Environmental Studies. International Books, 1997

CARNEIRO, R. A theory of the origin of the state. Science, n. 169(3947), p. 733$738,1970$.

GLASSOW, M. A. The Concept of Carrying Capacity in the Study of Culture Process. New York: Academic Press, 1978.

HARDIN, G. The tragedy of the commons. In: NELISSEN, N.; VAN DESSTRAATEN, J.; KLINKERS, L. Classics in Environmental Studies. International Books, 1997.

HUGILL, P. Technology and Geography in the elaboration of capitalism. In: World Trade Since 1431. Baltimore: Johns Hopkins Univerty Press, 1993.

MUNFORD, L. Thecnics and civilization. New York: Charles Scribners, 1934.

NETTING, R. Cultural Ecology. Ma. Benjamin Cummings Reading, 1977.

Intensive agriculture, population density, markets and the smallhoulder adaptation. Standford: Standford University Press, 1993.

OPHULS, W.; BOYAN, A. Stephen. Ecology and the politics of Scarcity Revisited. New York: W. H. Freeman and Company, 1992.

NORTH, D. C. Institutions and the performance of economies over time. In: MÉNARD, Claude; SHIRLEY, Mary M. (Ed.). Handbook of new institutional economics. Netherlands: Springer, 2005.

OSTROM, E. Governing the commons. Cambridge: Cambridge University Press, 1990. 
OSTROM, E.; DIETZ, T.; DOLŠAK, N.; STERN, P. C.; STONICH, S.; WEBER, E. The drama of the commons. Washington, D.C., USA: National Academy Press, 2003. POLANYI, K. A grande transformação - as origens de nossa época. Rio de Janeiro: Campus, 1980.

ROOSEVELT, A. Determinismo ecológico na interpretação do desenvolvimento social indígena da Amazônia. In: NEVES, W. E. (org). Origens adaptações e diversidade biológica do homem nativo da Amazônia. Belém: MPEG; CNPq; SCT/PR, 1991.

STUART MILL, J. Sobre a liberdade. Rio de Janeiro: Nacional, 1942.

TAINTER, J. The collapse of complex societies. Cambridge: Cambridge University Press, 1988.

WILKINSON, R. A Revolução Industrial inglesa. In: Pobreza e progresso.

São Paulo: Zahar, 1974.

Texto submetido à Revista em 7.5.2010

Aceito para publicação em 20.10.2010 